\title{
ANALISIS PENGARUH KUALITAS PELAYANAN PADA LOYALITAS PELANGGAN DENGAN KEPUASAN PELANGGAN SEBAGAI VARIABEL MEDIASI
}

\author{
Wahyu Rusdiyanto ${ }^{*}$, Sri Suranti ${ }^{2}$ \\ ${ }^{1}$ Fakultas Ekonomi, Universitas Negeri Yogyakarta, Indonesia \\ wahyu_rusdiyanto@uny.ac.id ${ }^{1}$,busri.suranti@gmail.com ${ }^{2}$ \\ *Corresponding author
}

\begin{abstract}
Abstrak: Analisis Pengaruh Kualitas Pelayanan pada Loyalitas Pelanggan dengan Kepuasan Pelanggan debagai Variabel Mediasi. Kualitas pelayanan dalam dunia bisnis menjadi perhatian utama agar pelanggan merasa puas dan menjadi loyal. Studi ini bertujuan untuk menganalisis bagaimana kualitas pelayanan, dan kepuasan pelanggan memberikan pengaruh pada loyalitas pelanggan. Studi ini dilakukan di Kota Surakarta dengan menggunakan data primer yang dikumpulkan dengan kuesioner. Metode yang digunakan adalah penelitian eksplanatori dengan pendekatan kuantitatif. Jumlah responden penelitian yaitu 245 orang yang ditentukan menggunakan teknik random sampling. Uji hipotesis dilakukan dengan analisis regresi pada perangkat lunak SPSS. Uji mediasi menggunakan metode Barond and Kenny. Hasil analisis data menemukan bahwa (1) kualitas pelayanan mempunyai pengaruh yang positif pada kepuasan pelanggan, (2) kepuasan pelanggan mempunyai pengaruh yang positif pada loyalitas pelanggan, (3) kepuasan pelanggan menjadi mediator pengaruh kualitas pelayanan pada loyalitas pelanggan.
\end{abstract}

Kata kunci: analisis pengaruh, kualitas pelayanan, loyalitas pelanggan, kepuasan pelanggan, pelayanan prima

\begin{abstract}
Analysis of Effect of Service Quality on Customer Loyalty with Customer Satisfaction as a Mediation Variables. Service quality in the business world is a major concern so that customers feel satisfied and become loyal. This study aims to analyze how service quality and customer satisfaction influence customer loyalty. This study was conducted in the city of Surakarta, primary data collected by a questionnaire. The method used is explanatory research with a quantitative approach. The number of research respondents was 245 who were determined using random sampling technique. Hypothesis testing is carried out by means of regression analysis on SPSS software. The mediation test uses the Barond and Kenny method. The results of data analysis found that (1) service quality has a positive influence on customer satisfaction, (2) customer satisfaction has a positive influence on customer loyalty, (3) customer satisfaction becomes a mediator of the effect of service quality on customer loyalty.
\end{abstract}

Keywords: analysis of effect, service quality, customer loyalty, customer satisfaction, excellent service

\begin{tabular}{|c|c|c|c|c|c|}
\hline \multicolumn{6}{|c|}{ History \& License of Article Publication: } \\
\hline Received: & $06 / 01 / 2021$ & Revision: & $03 / 02 / 2021$ & Published: & $28 / 02 / 2021$ \\
\hline
\end{tabular}




\section{PENDAHULUAN}

Kota Surakarta (lebih dikenal dengan Solo) di Provinsi Jawa Tengah sudah terkenal sejak lama menjadi destinasi wisata favorit di Indonesia. Dinas Pariwisata Kota Surakarta mencatat adanya peningkatan jumlah wisatawan yang mengunjungi Kota Surakarta dari tahun 2015-2018 (Wasita, 2019). Dinas Pariwisata mencatat jumlah wisatawan pada tahun 2015 sebanyak 4.142 .785 wisatawan, dengan rincian 36.546 wisatawan mancanegara dan 4.106.239 merupakan wisatawan domestik. Selanjutnya, pada tahun 2016 jumlah wisatawan secara keseluruhan mencapai 4.395.550 wisatawan dengan rincian sebanyak 33.682 wisatawan asing dan 4.361.868 wisatawan domestik. Pada tahun 2017 jumlah wisatawan kembali meningkat menjadi 4.503.245 wisatawan yang terdiri dari 34.423 wisatawan asing dan 4.468.822 wisatawan lokal atau domestik. Pada tahun 2018 terdapat 4.695.820 wisatawan yang terdiri 38.537 wisatawan asing dan 4.657 .283 wisatawan lokal atau domestik. Data tersebut, tentu menjadi potensi dan peluang yang baik dalam pengembangan wisata kota solo.

Pada tahun 2018, sektor pariwisata di Indonesia menjadi penghasil devisa terbesar mengalahkan pendapatan dari sektor migas dan pekerja migran Indonesia (dulu dikenal dengan istilah Tenaga Kerja Indonesia/TKI). Keindahan alam dan keberagaman budaya di Indonesia menjadi daya tarik besar bagi para wisatawan untuk berkunjung. Menurut Kozak, et al. (2008) industri pariwisata diartikan sebagai perpaduan produk dan jasa yang dikombinasikan dan mempunyai potensi untuk memberikan sumbangan bagi perekonomian. Kota Solo menawarkan berbagai macam jenis wisata diantaranya wisata budaya (keraton, taman sriwedari, dll), wisata alam (tawangmangu dll), wisata belanja di pasara klewer dan wisata kuliner yang beraneka ragam. Wisata kuliner menjadi bagian yang tidak terpisahkan dari sebuah perjalanan wisata. Wisatawan tidak segan membelanjakan uangnya untuk membeli makanan setelah melakukan perjalanan wisata. Ditambah lagi dengan kebiasaan masyarakat Indonesia yang suka membeli buah tangan. Menurut Besra (2012), wisatawan belum merasa perjalanan wisatanya lengkap juka belum menikmati kuliner khas daerah yang mereka datangi. Oleh karrena itu, wisata-kuliner-sudah selayaknya-menjadi bagian penting dari jenis wisata di suatu daerah.

Pelaku industri menilai pesatnya bisnis kuliner di Surakarta atau Soloraya didukung oleh adanya kemajuan kota dan peningkatan gaya hidup masyarakat Solo (Indrawati, 2013). Kedatangan mahasiswa dari berbagai daerah yang meimba ilmu di kampus yang ada di Solo juga mendukung beragamnya pilihan kuliner. Perubahan interaksi sosial dan gaya hidup melalui berbagai jenis media sosial, beragamnya selera yang karena keragaman penduduk, 
dan tata cara dalam menikmati makanan membawa para pengusaha kuliner di Surakarta kepada konsep dan ide-ide baru. Tempat makan dihias dengan sedemikian rupa agar lebih reatif dan akan lebih disukai pelanggan yang membutuhkan kenangan yang diabadikan dalam foto.

Pada dasarnya, selama manusia hidup pasti membutuhkan makanan. Oleh karena itu, usaha di bidang kuliner adalah usaha yang dianggap tidak akan pernah berakhir. Kondisi ini menciptakan banyak peluang usaha-usaha baru di bidang kuliner sekaligus menciptakan banyak persaingan. Dalam persaingan tersebut, para pelaku usaha kuliner dituntut mampu untuk menciptakan sesuatu yang unik dan berbeda dari usaha sejenis. Pada persaingan dunia usaha yang semakin ketat dan dinamis, usaha kuliner harus berinovasi dalam menciptakan menu-menu yang lebih menarik, harga yang tetap bersaing serta menjaga kualitas pelayanan maupun kualitas makanan yang dihidangkan. Dalam penelitian lain menyebutlan bahwa faktor-faktor penting yang diperhatikan konsumen dalam memilih tempat kuliner adalah kualitas produk, harga dan lokasi (Isa et al., 2018; Mangifera et al., 2018). Berbagai upaya tersebut dilakukan agar konsumen (pelanggan) mau melakukan pembelian ulang dan tidak berpindah ke produk atau merek yang lain. Pelanggan menjadi aset yang sangat berharga di tengah persaingan yang semakin ketat (Satlita, 2015).

Kualitas layanan menjadi bagian penting yang selalu pelaku usaha berikan agar dapat mempertahankan konsumen dan memenangkan persaingan usaha. Kualitas layanan sendiri memiliki banyak definisi, (Cronin, J. \& Taylor, S., 1992) mendefiniskan kualitas layanan sebagai hasil perbandingan konsumen atas harapan dan kinerja dari sebuah layanan. Hal yang sama juga disebutkan dalam Normasari (2013) bahwa kualitas layanan merupakan hasil persepsi atas harapan konsumen dibandingkan dengan aktualisasi kinerja dari pelayanan.

Pelayanan yang berkualitas menjadi daya tarik pelanggan dalam mengonsumsi sebuah produk atau menggunakan sebuah jasa. Pada bisnis kuliner, selain mampu menyediakan menu makanan yang sesuai dengan keinginan dan kebutuhan pelanggan, pelayanan juga dapat dilihat dari seberapa cepat penyajian sebuah makanan. Pelaku bisnis kuliner harus berusaha keras menciptakan pelayanan yang berkualitas agar tetap mampu menghadapi persaingan. Menurut American-Society-for-Quality-Control ASQC) dalam (Rambat, 2001), kualitas diartikan sebagai keseluruhan-ciri dan karakteristik yang bersifat laten dari suatu produk atau jasa dalam hal kemampuan untuk memenuhi kebutuhan yang telah ditentukan. Kualitas pelayanan menjadi suatu perhatian yang harus terus diupayakan dan dijaga oleh sebuah bisnis atau usaha. Upaya tersebut dilakukan agar tetap mendapat kepercayaan pelanggan sehingga sebuah bisnis dapat bertahan dalam usia yang panjang. Faktor yang 
dapat dibangun untuk memaksimalkan kualitas pelayanan antara lain kepuasan pelanggan, kulaitas produk atau jasa, dan dimensi harga (Rosidah, 2011)

Keberhasilan sebuah usaha kuliner tidak luput dari peran andil yang melibatkan usaha rumah makan itu sendiri dan peran serta pelanggan dalam merekomendasikan kepada pelanggan lain. Beragamnya pola konsumsi dan gaya hidup pelanggan memberikan pengaruh pada usaha kuliner dalam memberikan pelayanan. Pelaku usaha kuliner sudah seyogyanya berusaha memberikan pelayanan yang baik dan berkualitas. Cheng et al. (2008) menegaskan bahwa kualitas pelayanan yang diberikan pelaku usaha mempunyai pengaruh terhadap kepuasan pelanggan. Pada situasi selanjutnya, kepuasan pelanggan mempunyai pengaruh terhadap kesetiaan pelanggan. Pengaruh dari ketiga variabel dalam penelitian itu adalah positif. Kepuasan pelanggan merupakan faktor penting dalam kemajuan bisnis apapun termasuk dalam bidang kuliner. Pelanggan yang merasa puas atau senang akan cenderung lebih loyal atau setia terhadap produk yang dihasilkan oleh usaha tersebut. Menciptakan loyalitas pelanggan adalah sebuah keharusan. Hal tersebut dimaksudkan untuk mendukung konsumen agar melakukan pembelian ulang dan tidak berpindah pada produk lain.

Kepuasan pelanggan juga menjadi perhatian utama di sektor usaha rumah makan dan usaha kuliner lain pada umumnya. Rasa puas yang menjadi pengalaman pelanggan akan mendorong mereka untuk melakukan pembelian ulang dan menceritakan kepada pelanggan lain. Pada kondisi sebaliknya, perasaan tidak puas yang dirasakan pelanggan mendorong timbulnya perasaan kecewa, berdampak pada tindakan tidak melakukan pembelian kembali dan pada titik tertentu akan menghentikan konsumsi sebuah produk atau jasa. Menurut Akbar \& Parvez (2009), kepuasan pelanggan muncul karena adanya pelayanan berkualitas tinggi. Studi dari Kandampully \& Suhartanto (2000) dan Jihan \& Made (2018) berhasil bahwa loyalitas pelanggan dipengaruhi langsung oleh kepuasan pelanggan. Hasil studi tersebut diperkuat oleh temuan Srivastava \& Rai (2013) dan Novianti et al. (2018) yang menemukan fakta bahwa pada dimensi tertetu, kepuasan pelanggan terbukti berperan sebagai medator hubungan kualitas layanan terhadap loyalitas pelanggan.

Loyalitas atau kesetiaan pelanggan menjadi topik kajian yang banyak diteliti ketika menelaah perusahaan bidang apapun dan dalam skala bisnis yang kecil sampai skala bisnis yang besar. Banyak penelitian yang telah membuktikan bahwa cara-cara elegan dalam mengikat pelanggan dapat membuat pelanggan berkembang atau bertambah, tidak hanya tetap sekedar bertahan (Maria et al., 2020). Usaha-usaha dalam mewujudkan kesetiaan pelanggan dipandang perlu memperhatikikan banyak faktor, Namun, usaha tersebut 
diproyeksikan dan diyakini berdampak pada kesukseskan yang besar dan berlangsung dalam waktu yang tidak sebentar. Perpindahan merek yang dilakukan pelanggan akan sulit terjadi apabila seorang pelanggan sudah setia/loyal. Loyalitas pelanggan dibentuk oleh banyak faktor yang mempengaruhinya. Faktor yang beragam dan tahapan yang tidak harus dilalui dalam membentuk kesetiaan pelanggan selalu menjadi bahan kajian yang menarik dan layak untuk terus diteliti. Pada studi ini, faktor yang dikaji dalam pembentukan loyalitas pelanggan adalah kulaitas layanan dan kepuasan pelanggan.

Penelitian dan studi tentang loyalitas pelanggan sudah banyak dilakukan. Kajian literatur yang membahas loyalitas pelanggan juga mudah ditemukan di berbagai buku. Loyalitas pelanggan telah menjadi bahan kajian yang menarik dalam dari puluhan tahun yang lalu. Parasuraman (1998) membentuk hubungan kausal antara persepsi kualitas layanan dan kepuasan pelanggan. (Ahmed et al., 2011) dalam penelitiannya menemukan bahwa karyawan yang puas tidak hanya menghasilkan pelanggan yang puas tetapi juga berdampak pada peningkatan profitabilitas, loyalitas karyawan dan kualitas layanan. Penelitian tersebut diperkuat oleh Mardikawati (2013) serta penelitian Widayatma \& Lestari (2018) yang berhasil mengidentifikasi dan menganalisis kepuasan pelanggan memberikan pengaruh dan berperan sebagai mediator kualitas layanan terhadap loyalitas pelanggan. Temuan yang sedikit berbeda terdapat dalam studi Cheng et al. (2008) yang tidak menemukan pengaruh langsung kualitas pelayanan pada kesetiaan atau loyalitas pelanggan, namun berpengaruh pada kepuasan pelanggan. Studi tersebut juga berhasil mengidentifikasi kepuasan pelanggan berpengaruh pada kesetiaan pelanggan.

Beberapa hasil studi juga menemukan hasil yang berbeda saat menganalisis peran kualitas pelayanan terhadap loyalitas atau kesetiaan pelanggan. Artikel ilmiah Budiarti (2017) berhasil mendigentifikasi bahwa loyalitas pelanggan dipengaruhi oleh kualitas layanan. Studi lain dilakukan oleh Gunawan \& Djati (2011) yang melakukan studi tentang pelayanan dan loyalitas di rumah sakit. Studi tersebut mengidentifikasi tentang kualitas layanan rumah sakit yang memberikan pengaruh tidak utuh (parsial) terhadap loyalitas pasien sebagai pelanggan rumah sakit. Kualitas layanan rumah sakit yang terdiri dari tampilan fisik, kehandalan, daya tanggap, jaminan, dan empati tidak semuanya memberikan pengaruh terhadap loyalitas pasien. Studi lain mendapatkan temuan yang berbeda. Studi yang dilakukan Aryani \& Rosinta (2010) menemukan bahwa loyalitas pelanggan tidak dipengaruhi oleh kualitas layanan. Studi lain yang mendukung temuan tersebut adalah hasil studi yang dilakukan oleh (Normasari, 2013) dan Purwati et al. (2020). 
Di Indonesia, pembentukan loyalitas pelanggan menjadi bahan kajian di berbagai disiplin ilmu. Loyalitas pelanggan sering diteliti untuk bidang ilmu komunikasi dan manajemen pemasaran. Selain itu, bidang administrasi perkantoran juga sering melakukan penelitian tentang lolayitas pelanggan yang berhubungan erat dengan topik pembahasan pelayanan prima. Perbedaan hasil pada beberapa penelitian sejenis layak menjadi bahan diskusi dan penelitian lebih lanjut. Banyaknya jumlah penelitian tentang suatu tema atau topik akan menambah khasanah pengetahuan dan pustaka ilmiah. Artikel ini akan membahas tentang (1) pengaruh kualitas pelayanan terhadap kepuasan pelanggan, (2) pengaruh kepuasan pelanggan terhadap kesetiaan pelanggan, dan (3) pengaruh kualitas pelayanan terhadap kesetiaan pelanggan melalui kepuasan pelanggan sebagai variabel mediasi.

\section{METODE}

Studi ini dilaksanakan di Kota Surakarta dengan pendekatan kuantitaif menggunakan metode eksplanatori. Alat yang digunakan dalam mengumpulkan data adalah kuiseoner berbentuk angket tertutup. Sampel penelitian adalah pelanggan bisnis kuliner dengan jumlah 245 orang. Sampel dipilih menggunakan teknik random sampling. Analisis data dalam pengujian hipotesis menggunakan analisis regresi berganda dengan taraf signifikansi $5 \%$. Uji mediasi mengadopsi model Baron \& Kenny (1986) dengan bantuan perangkat lunak SPSS. Variabel yang diukur dalam studi ini adalah kualitas pelayanan (Variabel X), kepuasan pelanggan (Variabel M), kesetiaan pelanggan (Variabel Y). Kerangka pemikiran dalam studi ini tersaji dalam gambar berikut:

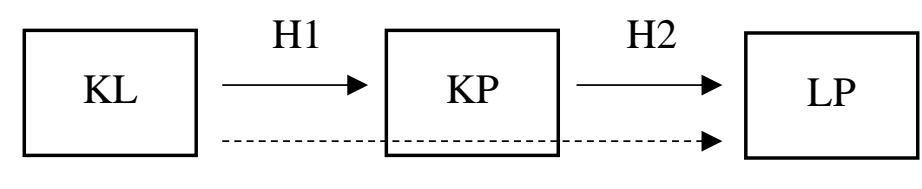

H3

Gambar 1. Kerangka Pikir

Mengacu pada kajian literatur dan hasil penelitian dan studi terdahulu yang disajikan di bagian pendahuluan, hipotesis yang diajukan adalah:

1. $\mathrm{H} 1$ : kualitas layanan (KL) berpengaruh positif pada kepuasan pelanggan (KP)

2. H2 : kepuasan pelanggan (KP) berpengaruh positif pada loyalitas pelanggan (LP)

3. H3 : kepuasan pelanggan (KP) memediasi pengaruh kualitas layanan (KL) pada loyalitas pelanggan (LP). 


\section{HASIL DAN PEMBAHASAN}

\section{Hasil Penelitian}

Pengujian hipotesis dalam studi ini dialakukan dengan analisis regresi menggunakan bantuan software SPSS versi 23. Dasar pengambilan keputusan uji hipotesis dalam studi ini adalah melihat $\mathrm{p}$ hitung dan signifikansinya. Dalam analisis regresi, hipotesis diterima apabila thitung lebih besar dari t tabel atau nilai probabilitas dan nilai signifikansi kurang dari taraf signifikansi yang ditetapkan (Ghozali, 2013). Rangkuman hasil uji hipotesis dalam studi ini tersaji dalam tabel 1 berikut:

Tabel 1. Uji Hipotesis

\begin{tabular}{ccccc}
\hline Hipotesis & Jalur Hubungan & Koefisien & $\mathrm{P}$ & Kesimpulan \\
\hline $\mathrm{H} 1$ & $\mathrm{KL} \Rightarrow \mathrm{KP}$ & 0.396 & 0.000 & Diterima \\
\hline $\mathrm{H} 2$ & $\mathrm{KP} \Rightarrow \mathrm{LP}$ & 0.156 & 0.036 & Diterima \\
\hline
\end{tabular}

Ditemukan koefisien regresi sebesar 0.396 (positif) dan nilai probabilitas (p) sebesar 0.000 untuk pengujian hipotesis 1 (KL terhadap KP). Nilai p yang menunjukkan $<0.05$ berarti signifikan pada taraf signifikansi $5 \%$. Hasil perhitungan tersebut mengindikasikan bahwa kualitas pelayananan (KL) memberikan pengaruh yang positif dan signifikan terhadap kepuasan pelanggan (KP). Hasil uji hipotesis kedua (KP terhadap LP) menemukan koefisien regresi sebesar 0.156 (positif) dan nilai p sebesar 0.036 . Nilai p yang menunjukkan $<0.05$ berarti signifikan pada taraf signifikansi 5\%. Hasil perhitungan tersebut mengindikasikan bahwa kepuasan pelanggan memberikan pengaruh positif dan signifikan terhadap kesetiaan atau loyalitas pelanggan. Perhitungan estimasi total effect dan direct effect berdasarkan kriteria Baron \& Kenny tersaji pada tabel 2 berikut:

Tabel 2. Hasil Estimasi Koefisien Total dan Direct Effect

\begin{tabular}{ccccc}
\hline Koefisien & Jalur Hubungan & Estimated & $\mathrm{P}$ & Kesimpulan \\
\hline $\mathrm{b}_{1}$ & $\begin{array}{c}\text { KL } \Rightarrow \text { KP } \\
(\text { direct } \text { effect })\end{array}$ & 0.396 & 0.000 & Signifikan \\
\hline $\mathrm{b}_{2}$ & $\begin{array}{c}\text { KP } \Rightarrow \text { LP } \\
(\text { direct } \text { effect })\end{array}$ & 0.156 & 0.036 & Signifikan \\
\hline $\mathrm{b}_{3}{ }_{3}$ & $\begin{array}{c}\text { KL } \Rightarrow \text { LP } \\
(\text { direct effect })\end{array}$ & 0.258 & 0.001 & Signifikan \\
\hline $\mathrm{b}_{3}$ & $\begin{array}{c}\text { KL } \Rightarrow \text { LP } \\
(\text { total } \text { effect })\end{array}$ & 0.319 & 0.000 & Signifikan \\
\hline
\end{tabular}

Perhitungan di Tabel 2 melengkapi hasil yang tersaji dalam tabel 1. Tabel 2 menunjukkan hasil regresi ketiga yang mengidentifikasi bahwa kualitas layanan (KL) 
berpengaruh signifikan pada loyalitas pelanggan (LP), setelah mengontrol variabel kepuasan pelanggan (KP) dengan koefisien regresi b2 sebesar 0,156 (positif). Selanjutnya ditemukan direct effect b'3 sebesar 0.258 (positif) yang lebih kecil (dalam harga mutlak) dari b3 =0.319 (positif). Tabel 2 juga menunjukkan koefisien pengaruh kualitas pelayanan (KL) terhadap kesetiaan pelanggan (LP) berkurang namun tetap signifikan dalam signifikansi 5\% setelah mengontrol variabel mediator kepuasan pelanggan (KP). Berdasarkan kriteria Baron dan Kenny (1986) maka dapat disimpulkan bahwa hipotesis variabel mediasi terbukti. Dengan demikian, studi ini menemukan kepuasan pelanggan yang berperan sebagai mediator. Dengan kata lain, pengaruh kualitas layanan terhadap loyalitas pelanggan dapat dimediasi oleh kepuasan pelanggan.

Hasil estimasi indirect effect menggunakan macro process disajikan pada tabel 3. Hasil estimasi indirect effect dari kualitas layanan (KL) terhadap loyalitas pelanggan (LP) melalui mediator kepuasan pelanggan (KP) pada tabel 2, diperoleh sebesar 0.062 (positif). Indirect effect dipopulasi terletak antara 0.002 (positif) dan 0.145 (positif) pada 95\% confidence interval. Tidak terdapat nilai 0 dalam confidence intervals $95 \%$ tersebut, maka dapat disimpulkan bahwa indirect effect signifikan pada level 0,05.

Tabel 3. Estimasi Indirect Effect dan 95\% Confidence Interval (CI)

\begin{tabular}{cccccc}
\hline \multirow{2}{*}{ Hipotesis } & \multirow{2}{*}{ Jalur Mediasi } & Koef. & \multicolumn{2}{c}{$95 \%$ CI } & \multirow{2}{*}{ Kesimpulan } \\
\cline { 4 - 5 } & & & Lower & Upper & \\
\hline $\mathrm{H}_{3}$ & KL $\Rightarrow$ KP $\Rightarrow$ LP & 0.062 & 0.002 & 0.145 & Signifikan \\
\hline
\end{tabular}

Berdasarkan hasil perhitungan dan mengacu pada kriteria Baron \& Kenny, kepuasan pelanggan terbukti menjadi mediator pengaruh kualitas pelayanan terhadap loyalitas pelanggan. Dengan kata lain, pengaruh kualitas pelayanan terhadap kesetiaan pelanggan dimediasi oleh kepuasan pelanggan. Dengan ditemukannya koefisien direct effect kualitas pelayanan terhadap kesetiaan pelanggan yang signifikan, berarti terjadi partial mediation. Hasil ini mendukung rumusan hipotesis yang telah dibangun sebelumnya.

\section{Pembahasan Hasil Penelitian}

Pengujian hipotesis pertama (H1) dengan analisis regresi berhasil mengidentifikasi pengaruh positif kualitas pelayanan terhadap kesetiaan atau loyalitas pelanggan. Kondisi tersebut dapat disimpulkan atau diibaratkan bahwa semakin baik atau semakin tinggi kualitas pelayanan yang dilakukan oleh pelaku usaha kuliner akan membuat pelanggan cenderung 
semakin setia atau loyal. Temuan ini memperkuat hasil studi Cheng et al. (2008) dan Budiarti (2017) yang menyatakan kualitas pelayanan memberikan pengaruh terhadap loyalitas pelanggan secara positif. Kualitas pelayanan dalam usaha di bidang kuliner paling sering dise but berfokus pada kecepatan pelayanan dan kenyamanan. Pada umumnya, konsumen datang ke tempat makan dalam kondisi lapar. Oleh karena itu, tidak mengherankan apabila aspek kecepatan layanan menjadi fokus dalam kualitas pelayanan di bisnis kuliner. Selain itu, aspek kenyamanan juga menjadi temuan yang sering muncul. Rasa makanan yang enak memang menjadi daya tarik utama bagi sebuah bisnis kuliner. Namun, tidak sedikit pelanggan yang datang ke sebuah tempat makan karena memepertimbangakan aspek kenyamanan. Baiknya kualitas pelayanan yang dirasakan dan diterima akan memikat hati pelanggan dan berpotensi membuat pelanggan lebih loyal.

Pengujian hipotesis kedua (H2) mendukung rumusan hipotesis yang telah dibangun sebelumnya yaitu kepuasan pelanggan berpengaruh positif pada kesetiaan pelanggan. Kondisi tersebut dapat disimpulkan diibaratkan semakin tinggi atau semakin baik kepuasan yang dirasakan pealnggan akan membuat pelanggan cenderung semakin setia atau loyal. Temuan dalam studi ini relevan dan mendukung studi yang dilakukan oleh Kandampully \& Suhartanto (2000), Cheng et al. (2008) dan Aryani \& Rosinta (2010). Dalam usaha di bidang apa pun, kepuasan pelanggan merupakan salah satu fokus yang harus dicapai. Dalam studi di bidang kuliner ini, kepuasan pelanggan mencakup aspek rasa, porsi dan harga. Temuan dalam studi ini sejalan dengan penelitian Riyadi (2014). Penelitian tersebut menyatakan bahwa penilaian pelanggan terhadap harga sebuah makanan didasarkan dengan membandingkan aspek rasa, porsi dan penampilan dari sebuah makanan dengan jumlah uang yang harus dibayarkan.

Kepuasan pelanggan harus menjadi prioritas dan fokus utama bagi setiap pelaku usaha. Baiknya pelayanan yang membuat pelanggan merasa puas akan membuat mereka segan dan berpikir berulang kali untuk berpindah ke tempat atau ke merek lain. Selain itu, pelanggan cenderung akan menyebarluaskan kepuasan yang dirasakan kepada orang lain. Berdasarkan kriteria uji mediasi Baron \& Kenny, hipotesis ketiga juga terbukti. Hasil analisis pada hipotesis ketiga (H3) menunjukkan kepuasan pelanggan menjadi mediator pengaruh kualitas pelayanan pada loyalitas atau kesetiaan pelanggan. Temuan ini memperkuat studi yang dilakukan oleh Widayatma \& Lestari (2018).

Hasil studi ini memperkuat fakta bahwa kepuasan pelanggan berpengaruh positif pada kesetiaan pelanggan. Pelanggan atau pembeli akan merasa puas setelah pembelian memperhitungkan tawaran oleh penjual dalam memenuhi harapan pembeli. Secara umum, 
banyak literatur yang mendefinisikan kepuasan pelanggan diukur dari munculnya perasaan senang atau kecewa. Perasaan tersebut muncul setelah melakukan perbandingan kinerja (hasil) dari sebuah produk atau jasa yang dipikirkan terhadap kinerja (hasil) yang diharapkan. Jika kinerja dari sebuah produk atau jasa tidak memenuhi harapan pelanggan, maka akan akan muncul rasa ketidakpuasan yang didorong oleh rasa kecewa. Kondisi sebaliknya, jika kinerja dari sebuah produk atau jasa dapat memenuhi harapan, maka pelanggan akan merasa puas. Dalam kondisi yang lebih baik, apabila kinerja sebuah produk atau jasa dapat melebihi harapan maka pelanggan akan merasa amat puas (Kotler \& Amstrong, 2003).

Hasil studi Amrullah (2018) tentang perilaku masyarakat yang melakukan pembelian makan di luar rumah di sejumlah negara (termasuk Indonesia) mengidentifikasi bahwa masyarakat yang makan di luar rumah satu sampai tiga kali dalam seminggu sebanyak 44\% dari jumlah responden. Jumlah tersebut lebih banyak $6 \%$ daripada masyarakat yang melakukannya sebulan sekali. Penelitian tersebut juga menyatakan bahwa sebanyak $60 \%$ masyarakat melakukan pemebelian makanan pada saat malam hari (Amrullah, 2018). Melihat fenomena tersebut, tidak mengherankan jika banyak kuliner yang memang baru buka saat malam hari. Kebutuhan makan dan minum masyarakat yang tidak akan pernah meredup menjadikan prospek bisnis kuliner tetap cerah. Bagi sebagian orang, menikmati sajian makanan dan minuman di luar rumah sudah menjadi salah satu sarana rekreasi dan hiburan pada saat pandemi seperti sekarang ini. Selain itu, wisata kuliner khas di sebuah daerah juga menjadi daya tarik tersendiri bagi beberapa wisatawan. Tidak sedikit wisatawan yang datang ke sebuah daerah dengan tujuan utama menikmati berbagai macam kuliner yang khas di daerah tersebut.

Variasi produk dan layanan dalam bisnis kuliner yang terus berkembang menjadi perhatian konsumen dalam menentukan apa yang akan mereka beli (Ratnasari et al., 2020). Pelanggan akan memilih penjual yang dapat memberikan kepuasan dan memenuhi harapan bagi mereka. Tugas utama perusahaan atau penjual adalah mempertahankan pelanggan yang ada dan menciptakan pelanggan baru. Dalam proses menciptakan kesetiaan pelanggan, perusahaan harus dapat memenuhi keinginan dan harapan pelanggan. Pelanggan akan membandingkan jumlah yang mereka bayar dengan apa yang mereka dapat. Pelanggan yang merasa puas atau senang terbukti memiliki kecenderungan yang tinggi untuk melakukan pembelian ulang. Pada jangka waktu tertentu, pembelian berulang yang dilakukan akan menciptakan ikatan emosional pelanggan dengan suatu merek, termasuk dalam konteks bisnis kuliner. Bahkan, pada level tertentu, pelanggan yang puas akan menunjukkan rasa 
memiliki (sense of belonging) pada sebuah merek. Kondisi tersebut adalah indikasi dari loyalitas pelanggan yang tinggi.

\section{KESIMPULAN}

Studi dan penelitian tentang variabel yang membentuk dan dapat memberikan pengaruh pada kesetiaan pelanggan telah banyak dilakukan. Terdapat banyak faktor yang dapat membebtuk, menumbuhkan dan mempengaruhi kesetiaan pelanggan. Dalam studi ini, faktor yang dibahas hanya terbatas pada kualitas pelayanan dan kepuasan pelanggan. Hasil dari studi memperkuat kajian yang sudah ada sebelumnya dengan berhasil mengidentifikasi adanya bukti: (1) pengaruh positif kualitas layanan terhadap kepuasan pelanggan, (2) pengaruh positif kepuasan pelanggan pada loyalitas pelanggan, (3) kepuasan pelanggan yang berperan sebagai variabel mediasi kualitas layanan dalam pengaruhnya pada loyalitas pelanggan. Kajian literatur mengenai faktor maupun variabel yang mempengaruhi kesetiaan pelanggan sudah sepantasnya tetap dilakukan mengingat perubahan perilaku pelanggan (konsumen) dari waktu ke waktu. Diskusi mengenai faktor dan variabel yang mempengaruhi kepuasan pelanggan dan kesetiaan pelanggan akan tetap menjadi topik yang menarik.

Temuan dalam penelitian hendaknya menjadi perhatian para pelaku bisnis kuliner atau pelaku usaha lain. Perhatian pelaku usaha terhadap loyalitas pelanggan dapat mengadopsi hasil penelitian yang sudah ada. Proses menciptakan loyalitas pelanggan akan menjadi tantangan bagi setiap pelaku usaha. Pelaku usaha kuliner disarankan memperhatikan kecepatan pelayanan dan kebersihan tempat usaha agar pelanggan merasa nyaman. Penelitian ini belum membedakan dan mengidentifikasi hasil dari perbedaan karakteristik pelanggan. Karakteristik pelanggan yang mempunyai perbedaan latar belakang pendidikan, kondisi sosial-ekonomi, umur dapat menghasilkan hasil penelitian yang berbeda. Peneliti berharap pada penelitian selanjutnya terdapat kajian yang mampu menampung perbedaan karakteristik pelanggan tersebut.

\section{DAFTAR PUSTAKA}

Ahmed, I., Razzaque, R., \& Ramzan, M. (2011). Examining the links between employee and customer variables of service profit chain: A case of Pakistani banks. Australian Journal of Basic and Applied Sciences, 5(11), 1634-1645.

Akbar, M. M., \& Parvez, N. (2009). Impact of Service Quality, Trust , and Customer Can Service Quality, Trust, and Customer Satisfaction on Customers Loyalty Satisfaction Engender Customers Loyalty? ABAC Journal, 29(1), 24-38. 
Amrullah, W. (2018). Pengaruh Experiential Marketing Terhadap Loyalitas Pelanggan Melalui Kepuasan Pelanggan Sebagai Variabel Intervening Di Sengkaling Kuliner "Sekul" Malang. Manajemen Bisnis, 7(2), 119-128. https://doi.org/10.22219/jmb.v7i2.7006.

Aryani, D., \& Rosinta, F. (2010). Pengaruh kualitas layanan terhadap kepuasan pelanggan dalam membentuk loyalitas pelanggan. Jurnal Ilmu Administrasi Dan Organisasi, 17(2), 114-126.

Baron, R. M., \& Kenny, D. A. (1986). The Moderator-Mediator Variable Distinction in Social Psychological Research: Conceptual, Strategic, and Statistical Considerations. Journal of Personality and Social Psychology, 51(6), 1173-1182. https://doi.org/10.1007/BF02512353.

Besra, E. (2012). Potensi Wisata Kuliner Dalam Mendukung Pariwisata Di Kota Padang. Jurnal Riset Akuntansi Dan Bisnis, 12, 74-101.

Budiarti, A. (2017). Pengaruh Kualitas Layanan Dan Penanganan Keluhan Terhadap Kepuasan Dan Loyalitas Nasabah Bank Umum Syariah Di Surabaya. EKUITAS (Jurnal Ekonomi Dan Keuangan), 210. https://doi.org/10.24034/j25485024.y2011.v15.i2.2289.

Cheng, T. C. E., Lai, L. C. F., \& Yeung, A. C. L. (2008). The driving forces of customer loyalty: A study of internet service providers in Hong Kong. International Journal of E-Business Research, 4(4), 26-42. https://doi.org/10.4018/jebr.2008100103.

Cronin, J., J., \& Taylor, S., A. (1992). Measuring service quality: a re-examination and extension. Journal of Marketing, 56(3), 55-68.

Ghozali, I. (2013). Ghozali, Imam (2013). Aplikasi Analisis Multivariate Dengan Program IBM SPSS 21Update PLS Regresi. Semarang: Badan Penerbit Universitas Diponegoro.

Gunawan, K., \& Djati, S. P. (2011). Kualitas Layanan dan Loyalitas Pasien (Studi pada Rumah Sakit Umum Swasta di Kota Singaraja-Bali). Jurnal Manajemen Dan Kewirausahaan, 13(1). https://doi.org/10.9744/jmk.13.1.32-39.

Indrawati, T. (2013). Bisnis Kuliner Solo Makin Ramai. Solopos. https://www.solopos.com/bisnis-kuliner-solo-makin-ramai-462099.

Isa, M., Mardalis, A., \& Mangifera, L. (2018). Analisis Keputusan Konsumen Dalam Melakukan Pembelian Makanan dan Minuman di Warung Hik. Jurnal Manajemen Dayasaing, 20(1), 44-51. https://doi.org/10.23917/dayasaing.v20i1.6590.

Jihan, N., \& Made, S. I. (2018). Analisis pengaruh kualitas layanan, harapan kinerja dan citra perusahaan terhadap loyalitas pelanggan melalui kepuasan pelanggan sebagai variabel intervening (Studi pada Rumah Sakit Islam Sultan Agung Semarang). Diponegoro Journal of Management, 7(1984), 8.

Kandampully, J., \& Suhartanto, D. (2000). Customer loyalty in the hotel industry: The role of customer satisfaction and image. International Journal of Contemporary Hospitality Management, 12(6), 346-351. https://doi.org/10.1108/09596110010342559. 
Kotler, P., \& Amstrong, G. (2003). Manajemen Pemasaran. In Jakarta.

Kozak, M., Gnoth, J., Andreu, L., Camprubí, R., Guia, J., \& Comas, J. (2008). Destination networks and induced tourism image. Tourism Review, 63(2), 47-58. https://doi.org/10.1108/16605370810883941.

Mangifera, L., Isa, M., \& Wajdi, M. F. (2018). Faktor-Faktor yang Mempengaruhi Konsumen Dalam Pemilihan Kuliner di Kawasan Wisata Alam Kemuning. Jurnal Manajemen Dayasaing, 20(1). https://doi.org/10.23917/dayasaing.v20i1.6415.

Mardikawati, W. (2013). PENGARUH NILAI PELANGGAN DAN KUALITAS LAYANAN TERHADAP LOYALITAS PELANGGAN, MELALUI KEPUASAN PELANGGAN PADA PELANGGAN BUS EFISIENSI (Studi PO Efisiensi Jurusan Yogyakarta-Cilacap). Jurnal Administrasi Bisnis, 2(1), 64-75. https://doi.org/10.14710/jab.v2i1.5355.

Maria, S., Permadi Hakim, Y., \& Caisar Darma, D. (2020). Perceptions of Service Quality and Corporate Image Against Satisfaction and Customer Loyalty. KnE Social Sciences, 2020, 9-25. https://doi.org/10.18502/kss.v4i3.6371.

Normasari, S. (2013). PENGARUH KUALITAS PELAYANAN TERHADAP KEPUASAN PELANGGAN, CITRA PERUSAHAAN DAN LOYALITAS PELANGGAN Survei padaTamu Pelanggan yang Menginap di Hotel Pelangi Malang. Jurnal Administrasi Bisnis S1 Universitas Brawijaya, 6(2), 77767.

Novianti, N., Endri, E., \& Darlius, D. (2018). Kepuasan Pelanggan Memediasi Pengaruh Kualitas Pelayanan Dan Promosi Terhadap Loyalitas Pelanggan. Mix: Jurnal Ilmiah Manajemen, 8(1), 90. https://doi.org/10.22441/mix.2018.v8i1.006.

Parasuraman, A. (1998). PARASUMARAN 1998 - Customer service in business to business markets an agenda for research.pdf. 13(4), 309-321.

Purwati, A. A., Fitrio, T., Ben, F., \& Hamzah, M. L. (2020). Product Quality and After-Sales Service in Improving Customer Satisfaction and Loyalty. Jurnal Economia, 16(2), 223235. https://doi.org/10.21831/economia.v16i2.31521.

Rambat, L. (2001). Manajemen Pemasaran Jasa teori dan praktik. Salemba Empat, Jakarta.

RATNASARI, S. L., SUSANTI, E. N., ISMANTO, W., TANJUNG, R., DARMA, D. C., \& SUTJAHJO, G. (2020). An Experience of Tourism Development: How is the Strategy? Journal of Environmental Management and Tourism Journal, XI(7 (47)), 1877-1886.

Riyadi, B. S. U. A. N. H. (2014). Pengaruh Produk Restoran terhadap kepuasan Pelanggan. Jurnal Manejemen Resort \& Lesure, 11(2).

Rosidah. (2011). Upaya Peningkatan Kualitas Pelayanan dalam Organisasi. Efisiensi, XI(2), $35-45$.

Satlita, L. (2015). Pelayanan Prima untuk Membangun Loyalitas Pelanggan. In Efisiensi Kajian Ilmu Administrasi (Vol. 3, Issue 2). https://doi.org/10.21831/efisiensi.v3i2.3799. 
Srivastava, M., \& Rai, A. K. (2013). Investigating the Mediating Effect of Customer Satisfaction in the Service Quality - Customer Loyalty Relationship. Journal of Consumer Satisfaction, Dissatisfaction and Complaining Behavior, 26, 95.

Wasita, A. (2019). Jumlah wisatawan ke Solo sejak 2015 terus meningkat. ANTARA JATENG. https://jateng.antaranews.com/berita/274760/jumlah-wisatawan-ke-solosejak-2015-terus-meningkat.

Widayatma, C. P., \& Lestari, S. P. (2018). Konsumen Dengan Kepuasan Konsumen Sebagai Variabel Intervening (Studi Kasus Pada Rifa Kuliner Kendal). Serat Acitya - Jurnal Ilmiah UNTAG Semarang, 7(3), 25-38. https://doi.org/ISSN : 2302-2752, Vol. 7 No. 3, 2018.

\section{UCAPAN TERIMA KASIH}

Penulis mengucapkan terima kasih kepada: 1) Penulis penelitian terdahulu; 2) Responden penelitian; dan 3) Pengusaha rumah makan dan pengusaha kuliner lain yang mengizinkan pelaksanaan penelitian.

\section{PROFIL PENULIS}

Wahyu Rusdiyanto, Dosen jurusan Pendidikan Administrasi FE UNY dengan minat studi utama Manajemen SDM dan Administrasi Perkantoran. Akun SINTA ID: 6053771. Akun Google Scholar: http://bit.ly/GSWahyu, Sri Suranti, Guru di Sukoharjo. Mengambil program studi Magister Manajemen dengan peminatan utama Manajemen SDM. 